OPEN ACCESS

Edited by:

Fushun Wang,

Nanjing University of Chinese Medicine, China

Reviewed by:

Stephen Zhang,

University of Adelaide, Australia

Abida Sultana,

EviSyn Health, Bangladesh

${ }^{*}$ Correspondence:

Chunbo L

licb@smhc.org.cn

Hui L

lihuindyxs@163.com

†These authors have contributed equally to this work

Specialty section

This article was submitted to Psychology for Clinical Settings, a section of the journal Frontiers in Psychology

Received: 07 October 2020 Accepted: 24 March 2021 Published: 04 May 2021

Citation:

Li W, Zhang $\mathrm{H}$, Zhang $\mathrm{C}$, Luo J, Wang H, Wu H, Zhu Y, Cui H, Wang J, Li H, Zhu Z, Xu Y and Li C (2021) The

Prevalence of Psychological Status During the COVID-19 Epidemic in

China: A Systemic Review and Meta-Analysis.

Front. Psychol. 12:614964. doi: 10.3389/fpsyg.2021.614964

\section{The Prevalence of Psychological Status During the COVID-19 Epidemic in China: A Systemic Review and Meta-Analysis}

\author{
Wei Li ${ }^{1}$, Huijuan Zhang ${ }^{1}$, Caidi Zhang ${ }^{1}$, Jinjing Luo ${ }^{1}$, Hongyan Wang ${ }^{1}$, Hui Wu ${ }^{2}$, \\ Yikang Zhu ${ }^{1}$, Huiru Cui ${ }^{1}$, Jijun Wang ${ }^{1,3,4,5}$, Hui Li ${ }^{6 * t}$, Zhuoying Zhu ${ }^{1,5}$, Yifeng $X u^{1,5}$ and \\ Chunbo $\mathrm{Li}^{1,3,4,5 *+}$ \\ ${ }^{1}$ Shanghai Key Laboratory of Psychotic Disorders, Shanghai Mental Health Center, Shanghai Jiao Tong University School of \\ Medicine, Shanghai, China, ${ }^{2}$ Shanghai General Hospital, Shanghai Jiao Tong University School of Medicine, Shanghai, \\ China, ${ }^{3}$ Chinese Academy of Science Center for Excellence in Brain Science and Intelligence Technology, Chinese Academy \\ of Science, Shanghai, China, ${ }^{4}$ Brain Science and Technology Research Center, Shanghai Jiao Tong University, Shanghai, \\ China, ${ }^{5}$ Institute of Psychology and Behavioral Science, Shanghai Jiao Tong University, Shanghai, China, ${ }^{6}$ Shanghai Clinical \\ Research Center for Mental Health, Shanghai Mental Health Center, Shanghai Jiao Tong University School of Medicine, \\ Shanghai, China
}

The COVID-19 is creating panic among people around the world and is causing a huge public mental health crisis. Large numbers of observational studies focused on the prevalence of psychological problems during the COVID-19 pandemic were published. It is essential to conduct a meta-analysis of the prevalence of different psychological statuses to insight the psychological reactions of general population during the COVID-19 epidemic in China. Sixty six observational studies about the psychological statuses of people during the COVID-19 were included, searching up to 1 December 2020. Strengthening the Reporting of Observational Studies in Epidemiology (STROBE) was used to evaluate the quality of the included studies. OpenMeta[Analyst] was used for the data analysis. High prevalence of acute stress and fear symptoms were observed in the early period of the epidemic. Additionally, anxiety and depression symptoms continued at a high prevalence rate during the epidemic. It should alert the lasting mental health problems and the risk of post-traumatic stress disorder and other mental disorders.

Systematic Review Registration: PROSPERO CRD 42020171485.

Keywords: mental healthcare, COVID-19 pandemic, meta-analysis, psychological problems, PTSD

\section{INTRODUCTION}

The coronavirus disease (COVID-19) spread rapidly in China since it first appeared in Wuhan, China, in December 2019 (Liu et al., 2012). The acute respiratory infection caused by severe acute respiratory syndrome coronavirus 2 (SARS-CoV-2) has spread globally due to its high transmission rate (The Novel Coronavirus Pneumonia Emergency Response Epidemiology Team, 2020). On 11 March 2020, the WHO characterized COVID-19 as a pandemic. By 1 October 2020, the cumulative number of infections worldwide has exceeded 36 million, and the number of deaths has exceeded 1 million (World Health Organization, 2020). The COVID-19 is creating panic among people around the world and is causing a public mental health crisis (Dong and Bouey, 2020; Yao et al., 2020).

Looking back at the SARS outbreak in 2003 and the Ebola outbreak in 2014, not only did the incidence of psychological problems such as anxiety, fear, and stress increase during the epidemic 
period, but the psychological problems were also decelerating the recovery of infected patients (Person et al., 2004; Shultz et al., 2016). In addition, long-term follow-up revealed a significant increase in the incidence of mental disorders such as posttraumatic stress disorder and depression, especially among the health care workers (HCW) and survivors of the infection (Mak et al., 2009; Wu et al., 2009; Liu et al., 2012). Fear of illness and death, social isolation, and reduced income all contribute to the high incidence of mental and psychological problems during the emergence of epidemics (Carvalho et al., 2020). Therefore, targeted intervention according to the prevalence of mental and psychological problems during the epidemic has important social effects.

We conducted a meta-analysis of cross-sectional studies published before 6 March 2020 on the prevalence of different psychological states during early stage of COVID-19 epidemic in China (Li W. et al., 2020). The present study updated the literature retrieval date to 1 December 2020 to search more databases through a more comprehensive retrieval strategy. At the same time, the present study focuses on not only the prevalence of different psychological states, but also the difference of the prevalence among different periods of COVID19 pandemic. Based on the changes in the epidemic situation and the major events related to the psychological status of people, this study provides an evidence-based data for the prevention and control of the epidemic and psychological crisis intervention in the future.

\section{MATERIALS AND METHODS}

\section{Search Strategy}

We searched the following databases for studies published before 1 December 2020: PubMed, EMBASE, The Cochrane Library, EBSCO, Web of Science, medRxiv, PsycINFO, Chinese National Knowledge Infrastructure (CNKI), Chongqing VIP database for Chinese Technical Periodicals, WANFANG DATA, Chinese Biological Medical Literature Database, and official information release platform (WeChat Official Account or Weibo). The search terms are described in the Supplementary Material. The reference lists of included articles were hand-checked for further relevant studies, and experts in the field were asked about the ongoing studies.

\section{Inclusion and Exclusion Criteria}

All reports investigating the psychological status during the COVID-19 outbreak were screened using the following inclusion criteria: (a) the survey was carried out by using scales with good reliability and validity, and definite boundary values; (b) information about prevalence, sample size, and time of investigation or time of submission; (c) the survey was conducted after COVID-19 outbreak; (d) the survey was conducted among general population; (e) cross-sectional study; (f) studies published in either English or Chinese. The exclusion criteria were as follows: (a) incomplete outcome data or lack of valid data following contact with the original authors; (b) descriptive studies, qualitative studies, anthropologic studies, review articles, research protocols, case reports, and duplicated reports.

\section{Screening of Articles and Data Extraction}

Three researchers (CD.Z., JJ.L., and HY.W.) independently explored previous studies based on search terms. The retrieved records were managed by Endnote X9. After removing the duplicates, all titles and abstracts of the records were screened by the three independent researchers (CD.Z., JJ.L., and HY.W.), and all studies that could possibly meet the inclusion criteria according to one of the researchers were retrieved as full text. The decision to include or exclude a study was also made by the three independent researchers (CD.Z., JJ.L., and HY.W.). The disagreements were discussed and resolved through discussion with a third reviewer (YK. Z.).

The data were then extracted and checked by two independent reviewers (H.L. and W.L.) using a standardized data collection form. The pertinent data extracted included data source, publication date, sample size, investigation time, population, location, and method of investigation, where possible.

\section{Quality Assessment of the Studies}

The included studies were assessed using the Strengthening the Reporting of Observational Studies in Epidemiology (STROBE) checklist (Vandenbroucke et al., 2007), which includes 22 items for evaluating the title and abstract, introduction, methods, results and discussion, while assigning 1 point for each item, with a total of 22 points.

\section{Outcome Measures}

The primary outcome is the prevalence of different psychological statuses during the COVID-19 outbreak. The secondary outcomes are the prevalence of different psychological statuses in Hubei province and other provinces/cities outside the Hubei province.

\section{Categorization of Time Periods}

According to the dynamic changes in the situation and the major events related to the psychological status (Pan et al., 2020), we divided the epidemic into three time periods: the first period was from 23 January to 1 February 2020, during which the experts announced that the virus could be passed on, the government enforced lockdown in Wuhan, local traffic control and social isolation, and the hospitals faced serious shortages of medical resources and protective materials. The second period was from 2 February to 17 February, 2020, during which the Chinese government dispatched medical teams to Hubei Province for medical assistance, alleviated the shortage of medical resources and protective materials gradually, and set up psychological assistance hotlines in all provinces and cities throughout the country. The third period was from 18 February to 24 April, 2020. During this period, the number of patients recovered and discharged increased, and many provinces and cities down-regulated the level of emergency response to major public health emergencies and psychological medical teams to assist Wuhan.

\section{Analysis}

Meta-analyses were performed using the OpenMeta[Analyst] (Brown University, Rhode Island) (Lau et al., 1992; Viechtbauer, 


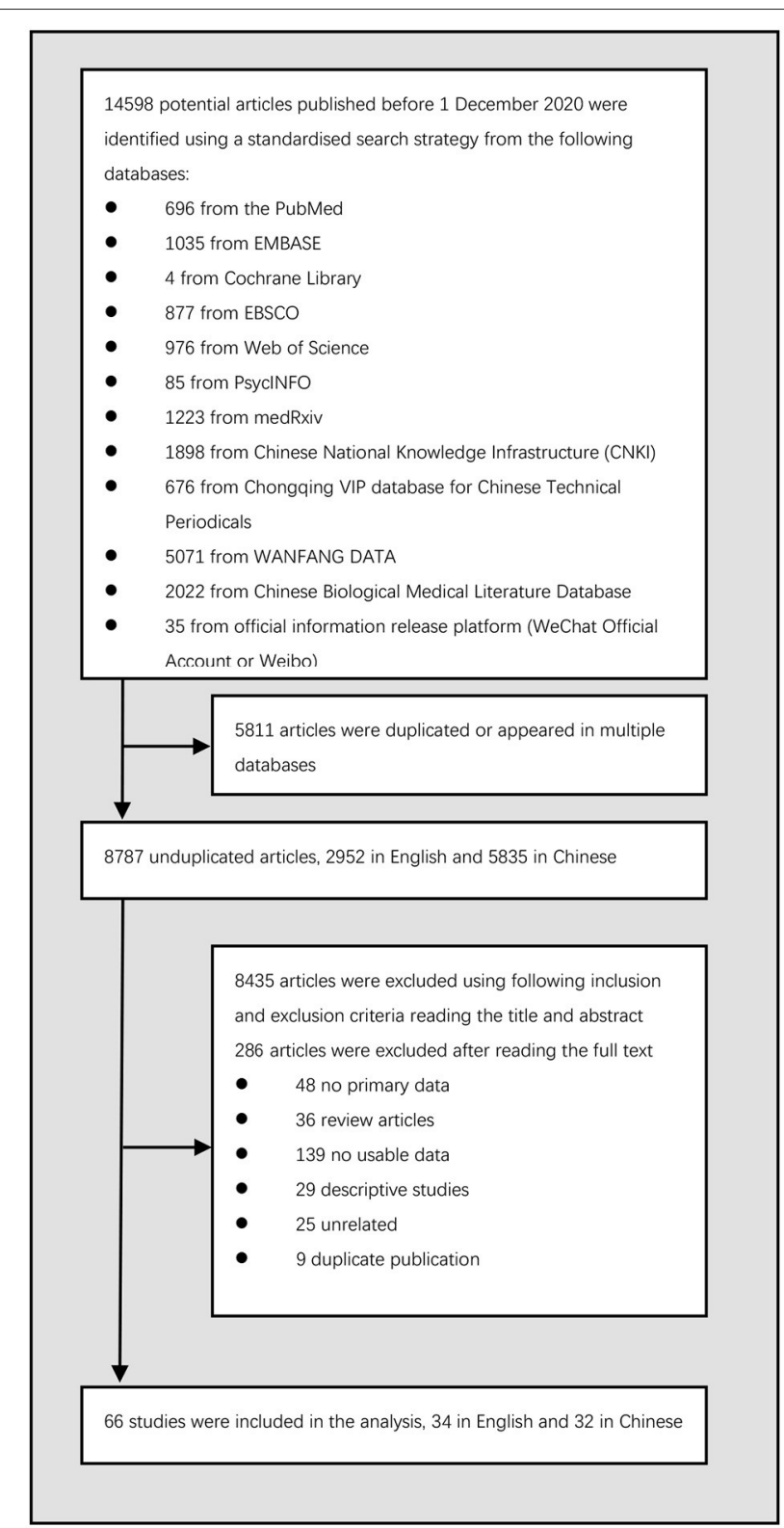

FIGURE 1 | Identification of included studies. epidemic, we performed the subgroup meta-analysis according to different periods.

For each meta-analysis, the heterogeneity was estimated using the inconsistency relative index $\mathrm{I}^{2}$, which describes the percentage of variation among studies by heterogeneity and not by chance. Values of $\mathrm{I}^{2}$ above 25,50 , and $75 \%$ were defined as low, moderate, and high heterogeneity, respectively (Higgins et al., 2011). Because the heterogeneity was high $\left(\mathrm{I}^{2}>\right.$ $75 \%$ ), we used the random effects model and the DerSimonianLaird method to interpolate the prevalence with a $95 \%$ confidence interval (CI) (Kristian et al., 2011). To identify the potential impact of small sample size $(<500)$, sensitivity analyses were performed.

\section{RESULTS}

\section{Characteristics of the Included Studies}

The process of identification of studies included in the analysis was shown in Figure 1. We found a total of 14,598 references in the databases. After removing these duplicates and studies that were reported in more than one article, 8,787 unduplicated articles remained. After reading the title and abstract of these unduplicated articles, we identified 8,435 articles that did not meet our inclusion and exclusion criteria, and after reading the full text, we identified an additional 286 articles that did not meet our criteria. This left us with 66 articles. Among these 66 studies, 34 in English and 32 in Chinese, were included in the subsequent analyses.

The characteristics of these 66 studies are shown in Table $\mathbf{1 .}$

The respondents of seven studies came from Hubei province (Cao H. et al., 2020; Fu et al., 2020; Huo et al., 2020; Luo F. et al., 2020; Yang T. et al., 2020; Yu et al., 2020; Zhou and Liu, 2020); the respondents of the thirteen studies came from provinces and cities other than Hubei province (Cao H. et al., 2020; Deng and Lei, 2020; Fu et al., 2020; Guo L. et al., 2020; Huo et al., 2020; Lin G. et al., 2020; Liu Z. et al., 2020; Sun Q. et al., 2020; Tan et al., 2020; Yang B. et al., 2020; Yang L. et al., 2020; Yang S. et al., 2020; Zhang J. et al., 2020).

\section{Quality Assessment of the Included Studies}

The STROBE evaluation results of the included studies showed that all of studies had scores $>11$, the lowest score was 12 (Qiu et al., 2020), and the highest score was 22 (Wang et al., 2020a). The average score was $(18.56 \pm 1.51)$, which is at the relatively good level.

\section{Findings From Meta-Analyses}

The Prevalence of Different Psychological Statuses During the COVID-19 Epidemic

A total of 53 studies investigated the prevalence of anxiety symptoms from 28 January to 15 April, 2020, and the prevalence was found to be $29.6 \%$ (95\% CI: 19.7-39.5\%). There were respectively 7,24 , and 22 studies to investigate the prevalence of anxiety symptoms during three periods of epidemic. The prevalence were found to be $26.2 \%$ (95\% CI: $19.3-33.1 \%$ ) in the 
TABLE 1 | Characteristics of the included studies.

\begin{tabular}{|c|c|c|c|c|c|c|c|}
\hline No. & Study & $\begin{array}{c}\text { Time of } \\
\text { investigation }\end{array}$ & $\begin{array}{l}\text { Age } \\
\text { (Mean } \pm \text { SD) }\end{array}$ & $\begin{array}{l}\text { Sex } \\
\text { (M/F) }\end{array}$ & $\begin{array}{l}\text { Location of } \\
\text { investigation }\end{array}$ & Questionnaires & Sample size \\
\hline 1 & Cai et al., 2020 & $1 / 31-2 / 4$ & Unavailable & $7404 / 14898$ & China & Self-compiled questionnaire & 22,302 \\
\hline 3 & Cao Y. et al., 2020 & $5 / 2-5 / 10$ & Unavailable & $127 / 303$ & Shanghai & IES & 430 \\
\hline 4 & Deng et al., 2020 & $2 / 13-2 / 16$ & $32.48 \pm 9.05$ & $226 / 254$ & China & SAS/SDS/SRQ & 480 \\
\hline 7 & Feng et al., 2020 & $2 / 17-3 / 10$ & Unavailable & Unavailable & China & SAS/SDS/AIS/PCL-C & 53,427 \\
\hline 8 & Fu et al., 2020 & $2 / 18-2 / 28$ & Unavailable & $376 / 866$ & Wuhan & GAD-7/PHQ-9/AIS & 1,242 \\
\hline 9 & Gao et al., 2020 & $1 / 31-2 / 2$ & $32.3 \pm 10.0$ & $1560 / 3267$ & China & WHO-5/GAD-7 & 4,827 \\
\hline 10 & Guo F. et al., 2020 & 2/18-2/22 & Unavailable & $15034 / 11683$ & China & CES-D/GAD-2 & 26,717 \\
\hline 11 & Guo L. et al., 2020 & $2 / 3-2 / 14$ & Unavailable & 3903/9919 & China & SCL-90/SASRQ & 13,822 \\
\hline 16 & Huo et al., 2020 & $2 / 9-2 / 14$ & Unavailable & $434 / 496$ & $\begin{array}{l}\text { Hubei and Yunnan } \\
\text { province }\end{array}$ & GAD-7/PHQ-9 & 930 \\
\hline 17 & Jiang et al., 2020a & $1 / 31-2 / 2$ & $39.6 \pm 12.1$ & $261 / 825$ & China & Self-compiled questionnaire & 1,086 \\
\hline 18 & Jiang et al., 2020b & 2/23-2/29 & $34.66 \pm 12.02$ & $25781 / 34418$ & China & SDS/SAI & 60,199 \\
\hline 19 & Li S. et al., 2020 & $2 / 16-2 / 23$ & Unavailable & $833 / 2168$ & China & GAD-7/PHQ-9 & 3,001 \\
\hline 20 & Li Y. et al., 2020 & 1/30-2/1 & $33.2 \pm 8.6$ & $209 / 768$ & China & GAD-7/PHQ-9 & 977 \\
\hline 21 & Liang et al., 2020 & $1 / 30$ & Unavailable & $223 / 361$ & China & PCL-C & 584 \\
\hline 22 & Lin G. et al., 2020 & $1 / 31-2 / 8$ & $27.7 \pm 10.9$ & $213 / 591$ & Hainan province & Self-compiled questionnaire & 804 \\
\hline 23 & Lin L. et al., 2020 & $2 / 5-2 / 10$ & Unavailable & Unavailable & China & GAD-7/PHQ-9/ASDS & 3,826 \\
\hline 24 & Lin L.-Y. et al., 2020 & $2 / 5-2 / 27$ & Unavailable & $1685 / 3956$ & China & GAD-7 /PHQ-9/ASDS/ISI & 5,641 \\
\hline 32 & Ran et al., 2020 & $2 / 23-3 / 2$ & $28.7 \pm 10.64$ & $586 / 1184$ & China & GAD-7 /PHQ-9/PHQ-15 & 1,770 \\
\hline 33 & Ren Y. et al., 2020 & $2 / 14-3 / 29$ & Unavailable & $360 / 812$ & China & $\begin{array}{l}\text { GAD-7/PHQ-9/SCL- } \\
\text { 90/PSS-10/ISI/PCL-5 }\end{array}$ & 1,172 \\
\hline 34 & Ren Z. et al., 2020 & $2 / 9-2 / 20$ & Unavailable & $2030 / 4100$ & China & GAD-7/PHQ-9 & 6,130 \\
\hline 35 & Shi et al., 2020 & $2 / 28-3 / 11$ & $35.97 \pm 8.22$ & $27149 / 29530$ & China & GAD-7/PHQ-9/ISI/ASDS & 56,679 \\
\hline 36 & Song F. et al., 2020 & $1 / 28-2 / 20$ & Unavailable & $553 / 525$ & China & SCL-90 & 1,078 \\
\hline 37 & Song L. et al., 2020 & $4 / 9-4 / 22$ & $35.35 \pm 6.61$ & $183 / 526$ & China & GAD-7/CES-D/ISI & 709 \\
\hline 38 & Sun et al., 2021 & $1 / 30-2 / 3$ & Unavailable & Unavailable & China & PCL-5 & 2,091 \\
\hline 39 & Sun M. et al., 2020 & $1 / 28-2 / 4$ & Unavailable & $323 / 887$ & China & GAD-7 & 3,111 \\
\hline 40 & Sun Q. et al., 2020 & 2/5-2/19 & Unavailable & $1162 / 1972$ & Except for Hubei province & GAD-7 /PHQ-9/ISI & 3,134 \\
\hline 41 & Tan et al., 2020 & $2 / 24-2 / 25$ & $30.8 \pm 7.4$ & $501 / 172$ & Chongqing & IES-R/DASS-21/ISI & 673 \\
\hline 42 & Tian et al., 2020 & $1 / 31-2 / 2$ & $35.01 \pm 12.8$ & $549 / 511$ & China & SCL-90 & 1,060 \\
\hline 43 & Wang C. et al., 2020 & $1 / 31-2 / 2$ & Unavailable & $396 / 814$ & China & IES-R/DASS & 1,210 \\
\hline 44 & Wang J. et al., 2020 & $2 / 4-2 / 18$ & Unavailable & $2824 / 3613$ & China & PSQI & 6,437 \\
\hline 45 & Wang M. et al., 2020 & $2 / 1-2 / 18$ & Unavailable & $576 / 925$ & China & GAD-7/PHQ-9/SRQ-20/ISI & 1,501 \\
\hline 46 & Wang et al., 2020a & $1 / 31-2 / 2$ & $32.32 \pm 9.98$ & $1560 / 3267$ & China & GAD-7/WHO-5 & 4,827 \\
\hline 47 & Wang et al., 2020b & 2/20-2/22 & Unavailable & $406 / 623$ & China & SAS/SDS & 1,029 \\
\hline 48 & Wu M. et al., 2020 & $2 / 13-2 / 29$ & Unavailable & $13304 / 11485$ & China & HADS & 24,789 \\
\hline 49 & Xiao et al., 2020 & $2 / 1-3 / 31$ & $25.05 \pm 9.18$ & $1037 / 2038$ & China & GAD-7/PHQ-9 & 3,075 \\
\hline 50 & Yang B. et al., 2020 & $2 / 2-2 / 3$ & Unavailable & $213 / 414$ & Sichuan province & GAD-7/PHQ-9 & 627 \\
\hline
\end{tabular}


TABLE 1 | Continued

\begin{tabular}{|c|c|c|c|c|c|c|c|}
\hline No. & Study & $\begin{array}{c}\text { Time of } \\
\text { investigation }\end{array}$ & $\begin{array}{l}\text { Age } \\
(\text { Mean } \pm \text { SD) }\end{array}$ & $\begin{array}{l}\text { Sex } \\
\text { (M/F) }\end{array}$ & $\begin{array}{l}\text { Location of } \\
\text { investigation }\end{array}$ & Questionnaires & Sample size \\
\hline 51 & Yang L. et al., 2020 & $2 / 1-2 / 9$ & Unavailable & $142 / 379$ & Fujian province & PQEEPH & 521 \\
\hline 52 & Yang S. et al., 2020 & $3 / 5-3 / 14$ & Unavailable & 1239/1196 & Deqing and Taizhou & GAD-7/PHQ-9 & 2,435 \\
\hline 53 & Yang T. et al., 2020 & 2/13-2/15 & Unavailable & $185 / 148$ & Wuhan & GAD-7/PHQ-9 & 333 \\
\hline 54 & Yang X. et al., 2020 & $2 / 1-2 / 4$ & $33.84 \pm 12.28$ & $542 / 1096$ & China & PSS & 1,638 \\
\hline 55 & Yang Y. et al., 2020 & 2/19-2/21 & Unavailable & $1548 / 1611$ & China & GHQ-20 & 3,159 \\
\hline 56 & Yu et al., 2020 & $2 / 17-2 / 27$ & Unavailable & $1180 / 1847$ & Enshi & SAS & 3,027 \\
\hline 57 & Zhang J. et al., 2020 & 2/10-2/15 & $36.45 \pm 2.14$ & $0 / 300$ & Changzhi & SCL-90 & 300 \\
\hline 58 & Zhang et al., 2020b & $2 / 1-2 / 5$ & Unavailable & $617 / 561$ & Wuhan & ISI & 1,178 \\
\hline 59 & Zhao et al., 2020 & 2/18-2/25 & $29.17 \pm 10.58$ & Unavailable & China & PSQI & 1,722 \\
\hline 60 & Zhen and Zhou, 2020 & $1 / 27-1 / 30$ & Unavailable & $361 / 689$ & China & Self-compiled questionnaire & 1,050 \\
\hline 61 & Zhong et al., 2020 & 2/13-2/24 & Unavailable & $5685 / 10363$ & China & SASRQ & 16,048 \\
\hline 62 & Zhou and Liu, 2020 & $3 / 2-3 / 5$ & $33.22 \pm 0.61$ & 73/138 & Hubei province & PQEEPH & 211 \\
\hline 63 & Zhu et al., 2020b & $2 / 5-2 / 7$ & $33 \pm 9$ & $380 / 996$ & China & SAS/SDS & 1,376 \\
\hline 64 & Zhu et al., 2020a & 2/19-2/26 & Unavailable & $424 / 568$ & China & SAS & 992 \\
\hline 65 & Zhu X. et al., 2020 & $1 / 30-2 / 13$ & Unavailable & $2176 / 4219$ & China & GAD-7/PHQ-9/SRQ-20 & 63,85 \\
\hline 66 & Zhu Z. et al., 2020 & 2/17-3/10 & Unavailable & $410 / 512$ & China & SCL-90 & 922 \\
\hline
\end{tabular}

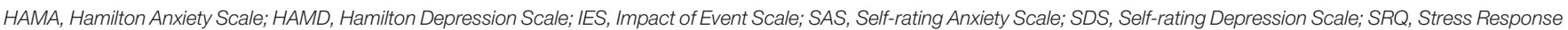

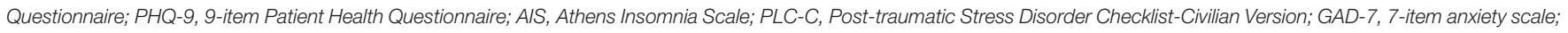

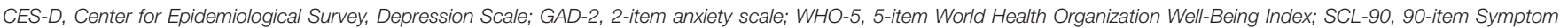

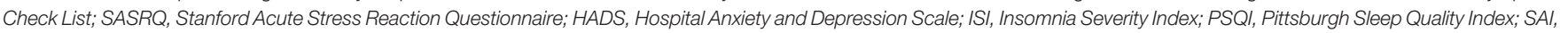

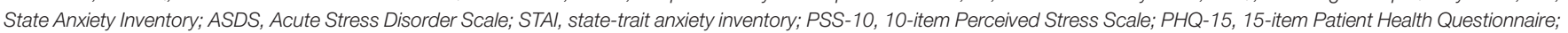

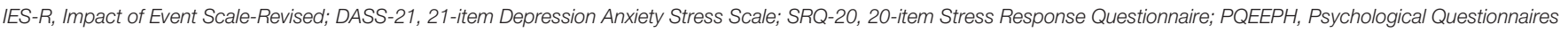
for Emergent Events of Public Health; PSS, Perceived Stress Scale; GHQ-20, General Health Questionnaire.

first period, $32.5 \%$ (95\% CI: $25.7-39.3 \%$ ) in the second period, and $27.4 \%$ (95\% CI: $14.6-40.3 \%)$ in the third period of epidemic (see in Figure 2A).

A total of 45 studies investigated the prevalence of depression symptoms from 31 January to 15 April, 2020, with a prevalence of $32.5 \%$ (95\% CI: $20.5-44.4 \%$ ). There were respectively 5, 20 and 20 studies to investigate the prevalence of depression symptoms during three periods of epidemic. The prevalence were found to be $31.4 \%$ (95\% CI: $16.9-45.9 \%)$ in the first period, $32.6 \%$ (95\% CI: $26.5-38.8 \%$ ) in the second period, and $32.5 \%$ (95\% CI: $15.3-49.6 \%$ ) in the third period of epidemic (see in Figure 2B).

A total of 15 studies investigated the prevalence of sleep problems from 3 February to 15 April, 2020, and the overall prevalence was found to be $26.3 \%$ (95\% CI: $13.0-39.6 \%$ ). There were respectively seven and eight studies to investigate the prevalence of sleep problems during the second and third period of epidemic. The prevalence were found to be $18.8 \%$ (95\% CI: $13.9-23.7 \%$ ) in the second period, and $32.8 \%$ (95\% CI: $13.6-$ $51.9 \%$ ) in the third period of epidemic (see in Figure 2C).

A total of 11 studies investigated the prevalence of acute stress symptoms from 1 February to 6 May, 2020, with a prevalence of $39.4 \%$ (95\% CI: 32.5-46.2\%). There were respectively 1, 4, and 6 studies to investigate the prevalence of acute stress symptoms during three periods of epidemic. The prevalence were found to be $75.5 \%$ (95\% CI: $73.1-78.0 \%$ ) in the first period, $24.1 \%$ (95\% CI: $15.0-33.3 \%$ ) in the second period, and $43.5 \%$ (95\% CI: $35.1-52.0 \%$ ) in the third period of epidemic (see in Figure 2D).
A total of nine studies investigated the prevalence of somatic symptoms from 1 February to 7 March, 2020, with a prevalence of $22.2 \%$ (95\%CI: $14.0-30.5 \%$ ). There were respectively 1, 4, and 4 studies to investigate the prevalence of somatic symptoms during three periods of epidemic. The prevalence were found to be $33.6 \%$ (95\% CI: 30.7-36.4\%) in the first period, $22.1 \%$ (95\% CI: $12.3-$ $32.0 \%$ ) in the second period, and $19.2 \%$ (95\% CI: $1.0-37.5 \%)$ in the third period of epidemic (see in Figure 2E).

A total of seven studies investigated the prevalence of fear symptoms from 1 February to 3 March, 2020, with a total incidence of $41.4 \%$ (95\% CI: $27.4-55.4 \%)$. There were respectively 1,4 , and 2 studies to investigate the prevalence of fear symptoms during three periods of epidemic. The prevalence were found to be $44.8 \%$ (95\% CI: $41.8-47.8 \%$ ) in the first period, $53.2 \%$ (95\% CI: 33.4-73.0\%) in the second period, and $16.0 \%$ (95\% CI: 13.7-18.3\%) in the third period of epidemic (see in Figure 2F).

A total of five studies investigated the prevalence of obsessive-compulsive symptoms from 1 February to 22 February, 2020, with a total incidence of 39.9\% (95\% CI: 11.0-68.7\%). There were respectively 1,3 , and 1 studies to investigate the prevalence of obsessive-compulsive symptoms during three periods of epidemic. The prevalence were found to be $59.6 \%$ (95\% CI: $56.7-62.6 \%)$ in the first period, $23.0 \%$ (95\% CI: 3.5-42.6\%) in the second period, and 69.9\% (95\% CI: $66.7-73.2 \%$ ) in the third period of epidemic (see in Figure 2G).

A total of six studies did not classify different psychological statuses, but used some comprehensive mental health 


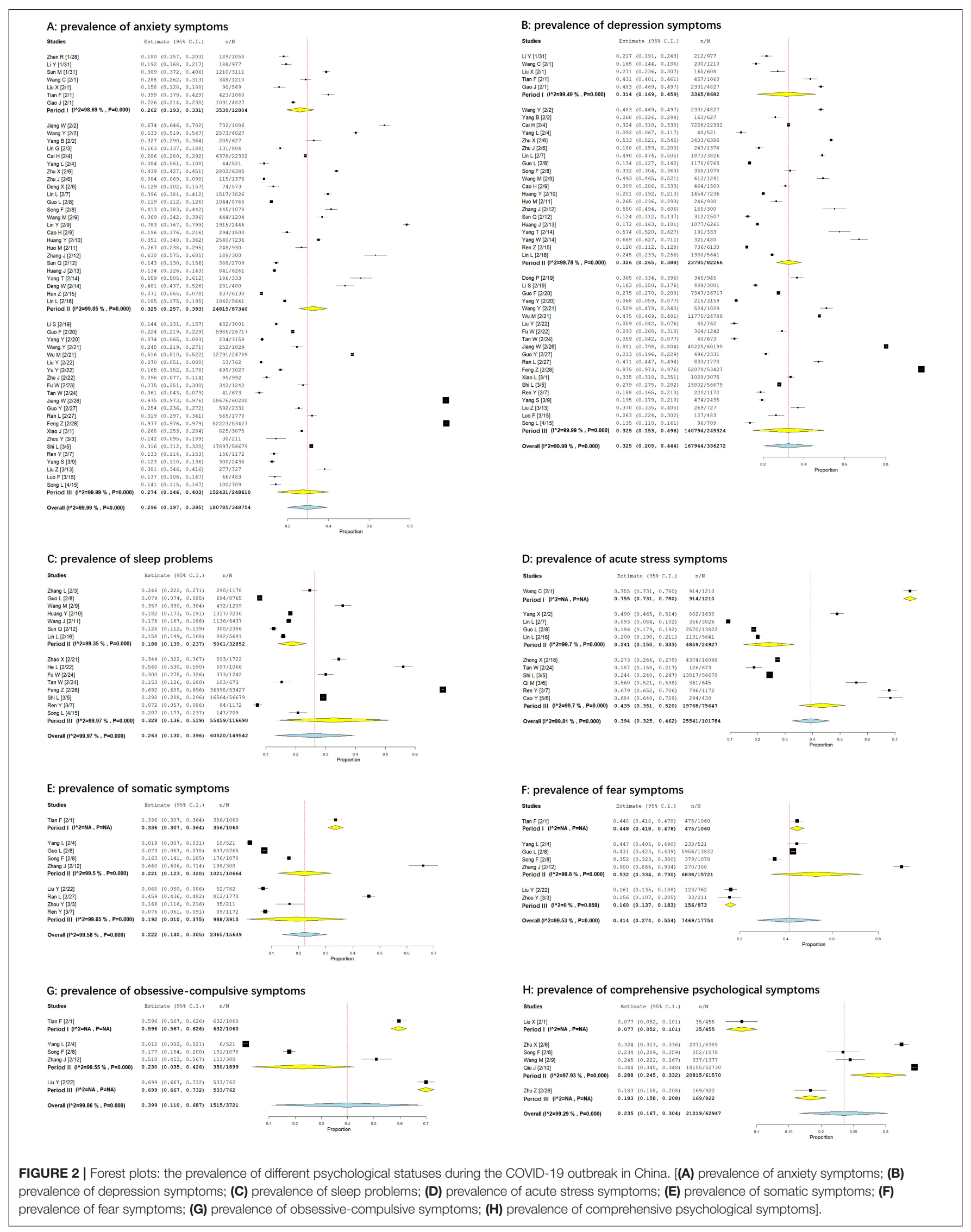


questionnaires to investigate it from 1 February to 26 February, 2020. The prevalence of comprehensive psychological symptoms was $23.5 \%$ (95\% CI: $16.7-30.4 \%$ ). There were respectively 1,4 and 1 studies to investigate the prevalence of comprehensive psychological symptoms during three periods of epidemic. The prevalence were found to be $7.7 \%$ (95\% CI: $5.2-10.1 \%$ ) in the first period, $28.8 \%$ (95\% CI: $24.5-33.2 \%$ ) in the second period, and $18.3 \%$ (95\% CI: $15.8-20.8 \%)$ in the third period of epidemic (see in Figure 2H).

\section{The Prevalence of Different Psychological Status in Hubei Province and Other Provinces/Cities Outside Hubei Province}

A total of six studies investigated the prevalence of anxiety symptoms in Hubei province from 9 February to 15 March, 2020 , with a prevalence of $24.7 \%$ (95\% CI: $16.4-32.9 \%$ ). A total of 13 studies investigated the prevalence of anxiety symptoms in provinces and cities other than Hubei province from 2 February to 13 March, 2020, with a prevalence of $21.6 \%$ (95\%CI: 17.1-26.1\%) (See in Figure 3A).

A total of five studies investigated the prevalence of depression symptoms in Hubei province. The investigation period was from 9 February to 15 March, 2020, with a prevalence of $34.7 \% \quad(95 \%$ CI: $26.2-43.1 \%)$. A total of 10 studies conducted investigations on the prevalence of depression symptoms in provinces and cities other than Hubei province, from 2 February to 13 March, 2020, with a prevalence of $22.5 \%$ (95\%CI: 17.6-27.5\%) (see in Figure 3B).

\section{Sensitivity Analyses}

The studies with small sample size (sample size < 500) were excluded for sensitivity analysis (Cao Y. et al., 2020; Deng et al., 2020; Luo F. et al., 2020; Yang T. et al., 2020; Zhang J. et al., 2020; Zhou and Liu, 2020). It was found that the results did not change in direction, indicating that the results were relatively stable (Table 2 and S2 in Supplementary Material).

\section{DISCUSSION}

Compared with previous meta-analysis studies focusing on the mental health during the Covid-19 outbreak (Hessami et al., 2020; Luo M. et al., 2020; Ren X. et al., 2020; Wu T. et al., 2020), the present study tried to show psychological statuses during different periods of epidemic through subgroup analysis. By reviewing the psychological conditions at different periods after the occurrence of the stress event of the COVID-19 epidemic, according to the results of our research, more targeted psychological assistance can be arranged at appropriate time point to help people during public emergent events.

An overview of the different psychological statuses during the COVID-19 epidemic in China showed that although the prevalence of acute stress symptoms reached a high level in the early stage of the epidemic, it gradually declined with the progress of the epidemic. However, the prevalence of anxiety and depression symptoms did not improve with the control of the epidemic, but still stayed at a high level, which was significantly higher than the average level of anxiety and depression according to the results from meta-analyses on prevalence of depression and anxiety in Chinese general population before the COVID-19 epidemic (Baxter et al., 2016; Guo et al., 2016; Wang et al., 2017). Previous studies found that anxiety and depression are risk factors for post-traumatic stress disorder (PTSD) (Grekin and O'hara, 2014; Song et al., 2018). Thus, the continued high prevalence of anxiety and depression symptoms during an epidemic may account for the elevated risk of long-term psychological problems (such as PTSD). Timely intervention for anxiety and depression during the epidemic is also helpful in preventing from the incidence of PTSD and related mental disorders.

In the early period of the COVID-19 epidemic, the public's response to the epidemic was not only reflected in the unknown pathogenic capacity and lethality of the virus, but also in the trust in the national public health response capacity and the effectiveness of personal protection measures (Dong and Bouey, 2020). Furthermore, with the promulgation of public health policies, such as the lockdown of the city, the blocking

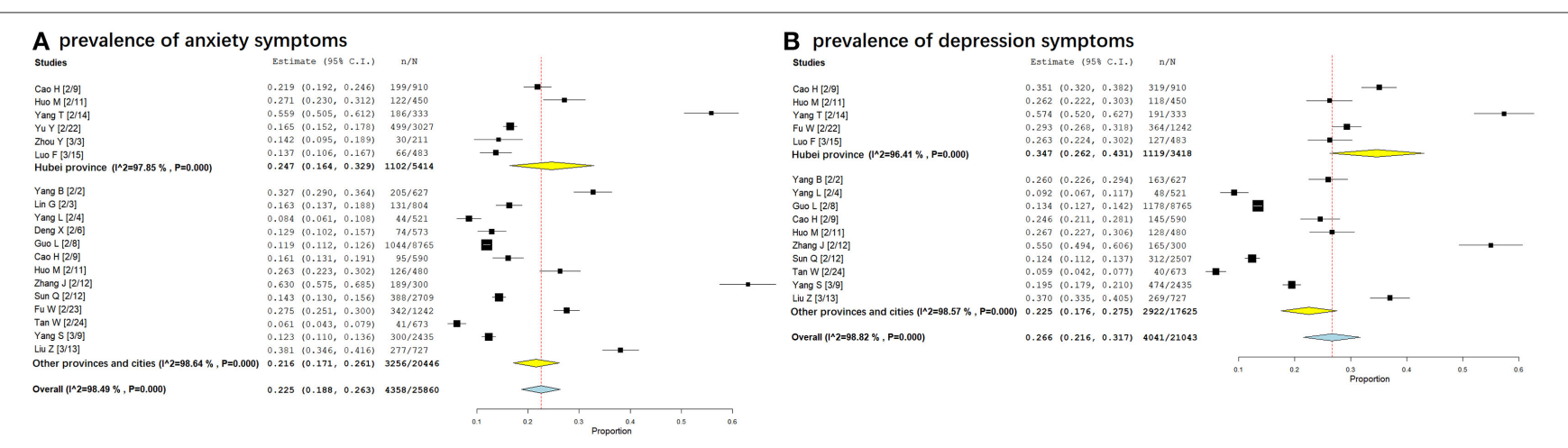

FIGURE 3 | Forest plots: the prevalence of anxiety and depression symptoms in Hubei province and other provinces/cities. [(A) prevalence of anxiety symptoms in Hubei province and other provinces/cities; (B) prevalence of anxiety symptoms in other provinces/cities outside Hubei province and other provinces/cities]. 
TABLE 2 | Sensitivity analysis: the prevalence of different psychological statuses after removing small-sample study.

\begin{tabular}{|c|c|c|c|c|}
\hline & $\begin{array}{c}\text { Period 1 } \\
\text { (23th Jan-1st Feb) }\end{array}$ & $\begin{array}{c}\text { Period } 2 \\
\text { (2nd Feb-17th Feb) }\end{array}$ & $\begin{array}{c}\text { Period } 3 \\
\text { (18th Feb-24th Apr) }\end{array}$ & Overall \\
\hline Anxiety symptoms & $\begin{array}{c}26.2 \% \\
(95 \% \text { Cl: } 19.3-33.1 \%)\end{array}$ & $\begin{array}{c}29.3 \% \\
\text { (95\% Cl: } 22.0-36.5 \%)\end{array}$ & $\begin{array}{c}28.8 \% \\
\text { (95\% Cl: } 15.4-42.2 \%)\end{array}$ & $\begin{array}{c}28.6 \% \\
\text { (95\% Cl: } 18.2-39.0 \%)\end{array}$ \\
\hline Depression symptoms & $\begin{array}{c}31.4 \% \\
\text { (95\% Cl: } 16.9-45.9 \%)\end{array}$ & $\begin{array}{c}28.0 \% \\
(95 \% \mathrm{Cl}: 21.5-34.4 \%)\end{array}$ & $\begin{array}{c}32.8 \% \\
\text { (95\% Cl: } 15.1-50.4 \%)\end{array}$ & $\begin{array}{c}30.6 \% \\
\text { (95\% Cl: } 18.1-43.1 \%)\end{array}$ \\
\hline Sleep problems & NA & $\begin{array}{c}18.8 \% \\
\text { (95\% Cl: } 13.9-23.7 \%)\end{array}$ & $\begin{array}{c}32.8 \% \\
(95 \% \text { Cl: } 13.6-51.9 \%)\end{array}$ & $\begin{array}{c}26.3 \% \\
\text { (95\% Cl: } 13.0-39.6 \%)\end{array}$ \\
\hline Acute stress symptoms & $\begin{array}{c}75.5 \% \\
\text { (95\% Cl: } 73.1-78.0 \%)\end{array}$ & $\begin{array}{c}24.1 \% \\
\text { (95\% Cl: } 15.0-33.3 \%)\end{array}$ & $\begin{array}{c}38.7 \% \\
\text { (95\% Cl: } 30.4-46.9 \%)\end{array}$ & $\begin{array}{c}36.5 \% \\
(95 \% \text { Cl: } 29.6-43.5 \%)\end{array}$ \\
\hline Somatic symptoms & $\begin{array}{c}33.6 \% \\
(95 \% \text { Cl: } 30.7-36.4 \%)\end{array}$ & $\begin{array}{c}8.4 \% \\
\text { (95\% Cl: } 2.8-14.0 \%)\end{array}$ & $\begin{array}{c}20.1 \% \\
(95 \% \mathrm{Cl}:-1.9-42.0 \%)\end{array}$ & $\begin{array}{c}17.0 \% \\
(95 \% \text { Cl: } 8.7-25.3 \%)\end{array}$ \\
\hline Fear symptoms & $\begin{array}{c}44.8 \% \\
(95 \% \mathrm{Cl}: 41.8-47.8 \%)\end{array}$ & $\begin{array}{c}40.9 \% \\
\text { (95\% Cl: } 35.5-46.4 \%)\end{array}$ & $\begin{array}{c}16.1 \% \\
\text { (95\% Cl: } 13.5-18.8 \%)\end{array}$ & $\begin{array}{c}36.8 \% \\
(95 \% \text { Cl: } 26.4-47.1 \%)\end{array}$ \\
\hline Obsessive-compulsive symptoms & $\begin{array}{c}59.6 \% \\
\text { (95\% Cl: } 56.7-62.6 \%)\end{array}$ & $\begin{array}{c}9.4 \% \\
(95 \% \text { Cl: }-6.8-25.6 \%)\end{array}$ & $\begin{array}{c}69.9 \% \\
\text { (95\% Cl: } 66.7-73.2 \%)\end{array}$ & $\begin{array}{c}37.1 \% \\
(95 \% \text { Cl: } 4.8-69.4 \%)\end{array}$ \\
\hline $\begin{array}{l}\text { Comprehensive psychological } \\
\text { symptoms }\end{array}$ & NA & $\begin{array}{c}28.8 \% \\
\text { (95\% Cl: } 24.5-33.2 \%)\end{array}$ & $\begin{array}{c}18.3 \% \\
(95 \% \mathrm{Cl}: 15.8-20.8 \%)\end{array}$ & $\begin{array}{c}26.7 \% \\
\text { (95\% Cl: } 21.6-31.8 \%)\end{array}$ \\
\hline \multicolumn{5}{|l|}{ Anxiety symptoms } \\
\hline Hubei province & & & & $\begin{array}{c}19.0 \% \\
\text { (95\% Cl: } 13.8-24.3 \%)\end{array}$ \\
\hline Other cities/provinces & & & & $\begin{array}{c}17.7 \% \\
\text { (95\% Cl: } 13.8-21.6 \%)\end{array}$ \\
\hline \multicolumn{5}{|l|}{ Depressive symptoms } \\
\hline Hubei province & & & & $\begin{array}{c}32.1 \% \\
\text { (95\% Cl: } 26.5-37.7 \%)\end{array}$ \\
\hline Other cities/provinces & & & & $\begin{array}{c}18.3 \% \\
\text { (95\% Cl: } 13.8-22.8 \%)\end{array}$ \\
\hline
\end{tabular}

NA: There was no study investigated the prevalence of the psychological status during the time period.

of traffic, and social isolation, the public's fear of COVID19 increased ( $\mathrm{Wu}$ et al., 2009). Therefore, the prevalence of fear and acute stress symptoms, the two acute psychological reactions to traumatic events, which quickly increased at the early period, and the prevalence was significantly higher than other psychological problems (Prati et al., 2012; Santos-Reyes and Gouzeva, 2020). Under the intervention of epidemic prevention and control at the national level, the prevalence of fear and acute stress symptoms decreased at the late period of epidemic.

Previous studies on the psychological reaction of the public during COVID-19 mentioned the "Psychological Typhoon Eye" effect (Yáñez et al., 2020; Zhang et al., 2020,a; Zhang S. X. et al., 2020). At the beginning of the epidemic, the residents in Hubei province did not realize the severity of the epidemic and felt that the virus was far away from them. The Hubei Provincial Government did not take strong measures in time. The information received by people is not symmetrical with the facts, it will cause greater panic later. This sent a false signal to the people: this new disease is not serious and can be prevented and controlled. Thus, the true situation of the epidemic was concealed. Furthermore, the residents outside the Hubei province appeared to be more anxious due to the asymmetry of information, and the media reported that the epidemic was very serious (Zhang et al., 2020a). This study did not found that the prevalence of anxiety and depression symptoms outside Hubei province were significantly higher than the prevalence inside Hubei province. However, the results of sensitivity analysis showed the prevalence of depression symptoms inside Hubei province is higher than the prevalence outside Hubei province. This may be related to the explosive increase of infected cases in Hubei province at the early stage of the epidemic, but the local government did not take active and effective measures to prevent the epidemic. However, few studies have been carried out on the prevalence of psychological statuses of residents in Hubei Province, which may be one of the reasons for the insignificant typhoon eye effect. Further researches are needed to show the effect in the future.

\section{LIMITATIONS}

However, the study had several limitations. Firstly, although we have tried to avoid the influence of noise on the results, some confounding factors may still influence the results. In order to reduce the impact of noise on the results, we used more stringent inclusion criteria. Therefore, the present study 
only focused studies conducted in general population, the study population may be more homogeneous, which may partly reduce the influence of possible noise. At the same time, all of the included studies were conducted quality assessment and were at the relatively good level. Additionally, in the sensitivity analysis, when we excluded the studies with small sample size to redo meta-analysis. It was found that the results did not change in direction, indicating that the results were relatively stable. For the longitudinal observation of the dynamic psychological status, the optimal way is to conduct a long-term cross-sectional survey of a specific population through systematic sampling. However, during the epidemic, it was difficult to restrict the population of investigation through an online survey. Additionally, the results of this current study show that there is significant heterogeneity among the studies. The heterogeneity is still large after subgroup analysis, which may be due to the fact that the included studies investigated very different population and settings.

\section{CONCLUSIONS}

There are different characteristics of the prevalence of psychological problems/symptoms during the COVID-19 epidemic. The persistently high prevalence of anxiety and depression symptoms during the epidemic could be a risk factor for PTSD and other mental disorders after the outbreak. Therefore, timely implementation of mental health policies is urgently needed for the public mental health crisis during the fight against COVID-19.

\section{REFERENCES}

Baxter, A. J., Charlson, F. J., Cheng, H. G., Shidhaye, R., Ferrari, A. J., and Whiteford, H. A. (2016). Prevalence of mental, neurological, and substance use disorders in China and India: a systematic analysis. Lancet Psychiatry 3, 832-841. doi: 10.1016/S2215-0366(16)30139-0

Cai, H., Zhu, Y., Lei, L., Pan, C., Zhu, L., Li, J., et al. (2020). Novel coronavirus pneumonia epidemic-related knowledge, behaviors and psychology status among college students and their family members and friends: an internetbased cross-sectional survey (in Chinese). Chin. J. Public Health 36, 152-155. doi: 10.11847 /zgggws 1128106

Cao, H., Zuo, C., Li, G., Huang, Y., Li, L., Huang, S., et al. (2020). A cross-sectional study of psychological status in different epidemic areas in China after the COVID-19 outbreak. Front. Psychiatry 11:575705. doi: $10.3389 /$ fpsyt.2020.575705

Cao, Y., Ma, Z. F., Zhang, Y., and Zhang, Y. (2020). Evaluation of lifestyle, attitude and stressful impact amid COVID-19 among adults in Shanghai, China. Int. J. Environ. Health Res. doi: 10.1080/09603123.2020.1841887. [Epub ahead of print].

Carvalho, P. M. D. M., Moreira, M. M., De Oliveira, M. N. A., Landim, J. M. M., and Neto, M. L. R. (2020). The psychiatric impact of the novel coronavirus outbreak. Psychiatry Res. Neuroimag. 286:112902. doi: 10.1016/j.psychres.2020.112902

Deng, W., Liu, Y., and Cheng, S. (2020). Investigation on psychological status of the people under coronavirus disease (in Chinese). J. North China Univ. Sci. Technol. 22, 482-488. doi: 10.19539/j.cnki.2095-2694.2020. 06.013

Deng, X., and Lei, L. (2020). A survey of public anxiety and health needs in Guangdong during the COVID-19 period (in Chinese). J. Med. Aesthetice Cosmetol. 29, 7-8.

\section{DATA AVAILABILITY STATEMENT}

The original contributions presented in the study are included in the article/Supplementary Material, further inquiries can be directed to the corresponding author/s.

\section{AUTHOR CONTRIBUTIONS}

CL and HL designed the study. WL, HL, and HZ were responsible for drafting the research searching strategy and data extraction. JL, CZ, YZ, and HW conducted the searching and screening of studies. WL drafted the manuscript. HL, HW, HC, JW ZZ, YX, and CL made critical revisions. All authors approved the final version for publication.

\section{FUNDING}

This work was funded by Shanghai Jiao Tong University Special Grant for the Prevention and Control of Novel Coronavirus (2020RK61), Shanghai Clinical Research Center for Mental Health (19MC1911100), and National Key R\&D Program of China (2018YFC2001605).

\section{SUPPLEMENTARY MATERIAL}

The Supplementary Material for this article can be found online at: https://www.frontiersin.org/articles/10.3389/fpsyg. 2021.614964/full\#supplementary-material

Dong, L., and Bouey, J. (2020). Public mental health crisis during COVID-19 pandemic, China. Emerg. Infect. Dis. 26, 1616-1618. doi: 10.3201/eid2607.202407

Dong, P., Ni, Z., Zhao, K., Sun, G., and Sun, H. (2020). Public depression status during the COVID-19 epidemic (in Chinese). Chin. Mental Health J. 34, 710-714. doi: 10.3969/j.issn.1000-6729.2020.8.014

Feng, Z., Liu, X., and Chen, Z. (2020). Analysis of characteristics of public psychological problems during COVID-19 epidemic (in Chinese). J. Southwest Univ. 46, 109-115. doi: 10.13718/j.cnki.xdsk.2020.04.013

Fu, W., Wang, C., Zou, L., Guo, Y., Lu, Z., Yan, S., et al. (2020). Psychological health, sleep quality, and coping styles to stress facing the COVID-19 in Wuhan, China. Transl. Psychiatry 10, 225-225. doi: 10.1038/s41398-020-00913-3

Gao, J., Zheng, P., Jia, Y., Chen, H., Mao, Y., Chen, S., et al. (2020). Mental health problems and social media exposure during COVID-19 outbreak. PLoS ONE 15:e0231924. doi: 10.2139/ssrn.3541120

Grekin, R., and O'hara, M. W. (2014). Prevalence and risk factors of postpartum posttraumatic stress disorder: a meta-analysis. Clin. Psychol. Rev. 34, 389-401. doi: 10.1016/j.cpr.2014.05.003

Guo, F., Cai, Y., Wang, Y., Li, Y., and Chen, Z. (2020). Emotional health status and social mentality of the Chinese general public during the 2019 novel coronavirus pneumonia pandemic (in Chinese). Sci. Technol. Rev. 38, 68-76. doi: 10.3981/j.issn.1000-7857.2020.04.009

Guo, L., Xu, P., Yao, F., Zhang, F., Qi, L., and Yang, F. (2020). The effect of acute stress disorder on negative emotions in chinese public during the NCP epidemic moderating effect of social support (in Chinese). J. Southwest Univ. 42, 21-30. doi: 10.13718/j.cnki.xdzk.2020.05.003

Guo, X., Meng, Z., Huang, G., Fan, J., Zhou, W., Ling, W., et al. (2016). Metaanalysis of the prevalence of anxiety disorders in mainland China from 2000 to 2015. Sci. Rep. 6:28033. doi: 10.1038/srep 28033 
Guo, Y., Cheng, C., Zeng, Y., Li, Y., Zhu, M., Yang, W., et al. (2020). Mental health disorders and associated risk factors in quarantined adults during the COVID19 outbreak in China: a cross-sectional study. J. Med. Internet Res. 22:e20328. doi: $10.2196 /$ preprints.20328

He, L., Gao, Y., Gao, X., and Lei, X. (2020). Sleep patterns and physical and mental health of residents during the COVID-19: susceptibility factors and coping strategies (in Chinese). J. Southwest Univ. 42, 11-20. doi: 10.13718/j.cnki.xdzk.2020.05.002

Hessami, K., Romanelli, C., Chiurazzi, M., and Cozzolino, M. (2020). COVID-19 pandemic and maternal mental health: a systematic review and meta-analysis. J. Matern Fetal Neonatal Med. doi: 10.1080/14767058.2020.1843155. [Epub ahead of print].

Higgins, J., Green, S., and Collaboration, C. (2011). Cochrane handbook for systematic reviews for interventions. Cochrane Database Syst. Rev. 2011:S38.

Huang, J., Liu, F., Teng, Z., Chen, J., Zhao, J., Wang, X., et al. (2020). Public behavior change, perceptions, depression, and anxiety in relation to the COVID-19 outbreak. Open Forum Infect. Dis. 7:ofaa273. doi: 10.1093/ofid/ofaa273

Huang, Y., and Zhao, N. (2020). Generalized anxiety disorder, depressive symptoms and sleep quality during COVID-19 outbreak in China: a web-based cross-sectional survey. Psychiatry Res. 288:112954. doi: 10.1016/j.psychres.2020.112954

Huo, M., Yin, Y., Jiang, L., and Duan, X. (2020). Survey on the mental status of inhabitants living in Wuhan, Huanggang, Kunmingand Yuxi during epidemic outbreak stage of COVID-19 (in Chinese). J. Int. Psychiatry 47, 197-200. doi: $10.13479 /$ j.cnki.jip.2020.02.002

Jiang, W., Fang, Y., Sun, F., Gao, Y., Sun, L., Yue, L., et al. (2020a). A Snapshot of the Mental State of Chinese Public During the 2019 Novel Coronavirus Outbreak [Gray Literature]. Shanghai: Shanghai Mental Health Center.

Jiang, W., Liu, X., Zhang, J., and Feng, Z. (2020b). Mental health status of Chinese residents during the COVID-19 epidemic. BMC Psychiatry 20:580. doi: 10.1186/s12888-020-02966-6

Kristian, T., Wetterslev, J., Awad, T., Thabane, L., and Gluud, C. (2011). Comparison of statistical inferences from the DerSimonian-Laird and alternative random-effects model meta-analyses - an empirical assessment of 920 cochrane primary outcome meta-analyses. Res. Synth. Methods. 2, 238-253. doi: $10.1002 / \mathrm{jrsm} .53$

Lau, J., Antman, E., and M. (1992). Cumulative meta-analysis of therapeutic trials for myocardial infarction. N. Engl. J. Med. 327, 248-254. doi: 10.1056/NEJM199207233270406

Li, S., Ye, Z., Du, C., Wei, Q., and He, C. (2020). The residents' mental health status and community's role during the COVID-19 pandemic: a community-based cross-sectional study in China. Ann. Transl. Med. 8:1321. doi: $10.21037 / \mathrm{atm}-20-6687$

Li, W., Zhang, C., Luo, J., Zhang, H., Wu, H., Yang, B., et al. (2020). Psychological status among different populations during COVID-19 epidemic: a systematic review and meta-analysis. J. Tongji Univ. 41, 147-154. doi: 10.16118/j.1008-0392.2020.02.002

Li, Y., Wang, X., Zhang, J., Du, S., and Zeng, L. (2020). Psychological survey of the general population during COVID-19 (in Chinese). Infect. Int. 9, 308-310.

Liang, L., Ren, H., Cao, R., Hu, Y., Qin, Z., Li, C., et al. (2020). The effect of COVID-19 on youth mental health. Psychiatr. Q. 91, 841-852. doi: 10.1007/s11126-020-09744-3

Lin, G., Zhao, C., Zhang, F., Feng, H., Lin, L., and Zhai, Y. (2020). Survey and analysis of anxiety of 804 residents in Hainan during the COVID-19 epidemic (in Chinese). J. Hainan Med. Univ. 26, 646-650. doi: 10.13210/j.cnki.jhmu.20200424.003

Lin, L., Wang, T., Pi, L., Chen, L., He, M., Yu, W., et al. (2020). Survey of emotion, stress and five viscera symptoms of population during the epidemic of Corona Virus Disease 2019 based on internet questionnaire (in Chinese). Chin. J. Tradit. Chin. Med. Pharm. 35, 1390-1394.

Lin, L.-Y., Wang, J., Ou-Yang, X.-Y., Miao, Q., Chen, R., Liang, F.-X., et al. (2020). The immediate impact of the 2019 novel coronavirus (COVID-19) outbreak on subjective sleep status. Sleep Med. 77, 348-354. doi: 10.1016/j.sleep.2020. 05.018

Lin, Y., Hu, Z., Alias, H., and Wong, L. P. (2020). Knowledge, attitudes, impact, and anxiety regarding COVID-19 infection among the public in China. Front. Public Health 8:236. doi: 10.3389/fpubh.2020.00236
Liu, X., Kakade, M., Fuller, C. J., Fan, B., Fang, Y., Kong, J., et al. (2012), Depression after exposure to stressful events: lessons learned from the severe acute respiratory syndrome epidemic. Compr. Psychiatry 53, 15-23. doi: 10.1016/j.comppsych.2011.02.003

Liu, X., Luo, W.-T., Li, Y., Li, C.-N., Hong, Z.-S., Chen, H.-L., et al. (2020). Psychological status and behavior changes of the public during the COVID-19 epidemic in China. Infect. Dis. Poverty 9, 58-58. doi: 10.1186/s40249-020-00678-3

Liu, Y., Chen, Y., and Luo, J. (2020). Study on the status of public mental health during the epidemic period of COVID-19 (in Chinese). J. Gannan Med. Univ. 40, 330-334. doi: 10.3969/j.issn.1001-5779.2020.04.002

Liu, Z., Zhang, X., Lv, Z., Liang, J., Deng, Y., and Feng, L. (2020). Mental health status and its influencing factors among general population and medical personnel in Guangdong Province during COVID-19 pandemic (in Chinese). J. Southern Med. Univ. 40, 1530-1537. doi: 10.12122/j.issn.1673-4254.2020.10.22

Luo, F., Luo, D., Wang, B., Lai, S., Chen, Y., Peng, W., et al. (2020). Analysis of anxiety and depression of residents outside Wuhan in Hubei Province during the outbreak of COVID-19 and its influencing factors (in Chinese). Chin. J. Dis. Control Prev. 24, 643-648.

Luo, M., Guo, L., Yu, M., Jiang, W., and Wang, H. (2020). The psychological and mental impact of coronavirus disease 2019 (COVID-19) on medical staff and general public - A systematic review and meta-analysis. Psychiatry Res. 291:113190. doi: 10.1016/j.psychres.2020.113190

Mak, I. W. C., Chu, C., Pan, P. C., Yiu, M. G. C., and Chan, V. L. (2009). Longterm psychiatric morbidities among SARS survivors. Gen. Hosp. Psychiatry 31, 318-326. doi: 10.1016/j.genhosppsych.2009.03.001

Pan, A., Liu, L., Wang, C., Guo, H., Hao, X., Wang, Q., et al. (2020). Association of public health interventions with the epidemiology of the COVID-19 outbreak in Wuhan, China. JAMA. 323, 1915-1923. doi: 10.1001/jama.2020.6130

Person, B., SY, F., Holton, K., Govert, B., Liang, A., Garza, B., et al. (2004). Fear and stigma: the epidemic within the SARS outbreak. Emerg. Infect. Dis. 10, 358-363. doi: $10.3201 /$ eid1002.030750

Prati, G., Catufi, V., and Pietrantoni, L. (2012). Emotional and behavioural reactions to tremors of the Umbria-Marche earthquake. Disasters 36, 439-451. doi: 10.1111/j.1467-7717.2011.01264.x

Qi, M., Li, P., Moyle, W., Weeks, B., and jones, C. (2020). Physical activity, health-related quality of life, and stress among the Chinese adult population during the COVID-19 pandemic. Int. J. Environ. Res. Public Health 17:6494. doi: 10.3390/ijerph17186494

Qiu, J., Shen, B., Zhao, M., Wang, Z., Xie, B., and Xu, Y. (2020). A nationwide survey of psychological distress among Chinese people in the COVID19 epidemic: implications and policy recommendations. Gen Psychiatr. 33:e100213. doi: 10.1136/gpsych-2020-100213

Ran, L., Wang, W., Ai, M., Kong, Y., Chen, J., and Kuang, L. (2020). Psychological resilience, depression, anxiety, and somatization symptoms in response to COVID-19: a study of the general population in China at the peak of its epidemic. Soc. Sci. Med. 262:113261. doi: 10.1016/j.socscimed.2020.113261

Ren, X., Huang, W., Pan, H., Huang, T., Wang, X., and Ma, Y. (2020). Mental health during the COVID-19 outbreak in China: a meta-analysis. Psychiatr. Q. 91, 1033-1045. doi: 10.1007/s11126-020-09796-5

Ren, Y., Qian, W., Li, Z., Liu, Z., Zhou, Y., Wang, R., et al. (2020). Public mental health under the long-term influence of COVID-19 in China: geographical and temporal distribution. J. Affect. Disord. 277, 893-900. doi: $10.1016 /$ j.jad.2020.08.045

Ren, Z., Zhou, Y., and Liu, Y. (2020). The psychological burden experienced by Chinese citizens during the COVID-19 outbreak: prevalence and determinants. BMC Public Health 20:1617. doi: 10.1186/s12889-020-09723-0

Santos-Reyes, J., and Gouzeva, T. (2020). Mexico city's residents emotional and behavioural reactions to the 19 September 2017 earthquake. Environ. Res. 186:109482. doi: 10.1016/j.envres.2020.109482

Shi, L., Lu, Z.-A., Que, J.-Y., Huang, X.-L., Liu, L., Ran, M.-S., et al. (2020). Prevalence of and risk factors associated with mental health symptoms among the general population in China during the coronavirus disease 2019 pandemic. JAMA Network Open 3:e2014053. doi: 10.1001/jamanetworkopen.2020.14053

Shultz, J. M., Cooper, J. L., Baingana, F., Oquendo, M. A., Espinel, Z., Althouse, B. M., et al. (2016). The role of fear-related behaviors in the 2013-2016 West Africa ebola virus disease outbreak. Curr. Psychiatry Rep. 18:104. doi: 10.1007/s11920-016-0741-y 
Song, F., Wang, X., Ju, Z., Liu, A., Liu, J., and Wang, T. (2020). Mental health status and related influencing factors during the epidemic of coronavirus disease 2019(COVID-19) (in Chinese). J. Public Health Prev. Med. 31, 23-27. doi: 10.3969/j.issn.1006-2483.2020.02.006

Song, J. Y., Jeong, K. S., Choi, K. S., Kim, M. G., and Ahn, Y. S. (2018). Psychological risk factors for posttraumatic stress disorder in workers after toxic chemical spill in gumi, South Korea. Workplace Health Saf. 66, 393-402. doi: 10.1177/2165079917750168

Song, L., Wang, Y., Li, Z., Yang, Y., and Li, H. (2020). Mental health and work attitudes among people resuming work during the COVID-19 pandemic: a cross-sectional study in China. Int. J. Environ. Res. Public Health 17:5059. doi: 10.3390/ijerph17145059

Sun, L., Sun, Z., Wu, L., Zhu, Z., Zhang, F., Shang, Z., et al. (2021). Prevalence and risk factors for acute posttraumatic stress disorder during the COVID-19 outbreak. J. Affect. Disord. 283, 123-129. doi: 10.1016/j.jad.2021.01.050

Sun, M., Li, S., Yue, H., Li, X., Li, W., and Xu, S. (2020). Analysis on anxiety status of Chinese netizens under the outbreak of the coronavirus disease 2019(COVID19) and its influencing factors (in Chinese). World Sci. Technol. Modern. Tradit. Chin. Med. 22, 703-708. doi: 10.11842/wst.20200301003

Sun, Q., Qin, Q., Chen, B., Shao, R., Zhang, J., and Li, Y. (2020). Stress, anxiety, depression and insomnia in adults outside Hubei province during the COVID-19 pandemic (in Chinese). Natl. Med. J. China 100, 3419-3424. doi: 10.3760/cma.j.cn112137-20200302-00557

Tan, W., Hao, F., Mcintyre, R. S., Jiang, L., Jiang, X., Zhang, L., et al. (2020). Is returning to work during the COVID-19 pandemic stressful? A study on immediate mental health status and psychoneuroimmunity prevention measures of Chinese workforce. Brain Behav. Immun. 87, 84-92. doi: 10.1016/j.bbi.2020.04.055

The Novel Coronavirus Pneumonia Emergency Response Epidemiology Team (2020). The epidemiological characteristics of an outbreak of 2019 novel coronavirus diseases (COVID-19)-China, 2020. China CDC Weekly 2, 113-122. doi: $10.46234 / \mathrm{ccdcw} 2020.032$

Tian, F., Li, H., Tian, S., Yang, J., Shao, J., and Tian, C. (2020). Psychological symptoms of ordinary Chinese citizens based on SCL-90 during the level I emergency response to COVID-19. Psychiatry Res. 288:112992. doi: 10.1016/j.psychres.2020.112992

Vandenbroucke, J. P., Von Elm, E., Altman, D. G., Gøtzsche, P. C., Mulrow, C. D., Pocock, S. J., et al. (2007). Strengthening the reporting of observational studies in epidemiology (STROBE). Epidemiology 18, 805-835. doi: 10.1097/EDE.0b013e3181577511

Viechtbauer, W. (2010). Conducting meta-analyses in R with the metafor package. J. Stat. Softw. 36:48. doi: 10.18637/jss.v036.i03

Wallace, B. C., Dahabreh, I. J., Trikalinos, T. A., Lau, J., Trow, P., and Schmid, C. H. (2012). Closing the gap between methodologists and end-users: $R$ as a computational back-end. J. Stat. Softw. 49:15. doi: 10.18637/jss.v049.i05

Wang, C., Pan, R., Wan, X., Tan, Y., Xu, L., Ho, C. S., et al. (2020). Immediate psychological responses and associated factors during the initial stage of the 2019 coronavirus disease (COVID-19) epidemic among the general population in China. Int. J. Environ. Res. Public Health 17:1729. doi: 10.3390/ijerph17051729

Wang, J., Gong, Y., Chen, Z., Wu, J., Feng, J., Yan, S., et al. (2020). Sleep disturbances among Chinese residents during the coronavirus disease 2019 outbreak and associated factors. Sleep Med. 74, 199-203. doi: 10.1016/j.sleep.2020.08.002

Wang, J., Wu, X., Lai, W., Long, E., Zhang, X., Li, W., et al. (2017). Prevalence of depression and depressive symptoms among outpatients: a systematic review and meta-analysis. BMJ Open 7:e017173. doi: 10.1136/bmjopen-2017-0 17173

Wang, M., Liu, X., Guo, H., Fan, H., Jiang, R., and Tan, S. (2020). Mental health of middle-aged and elderly population during outbreak of corona-virus disease 2019 (in Chinese). Chin. J. Mult. Organ Dis. Elderly 19, 241-245. doi: 10.11915/j.issn.1671-5403.2020.04.056

Wang, Y., Gao, J., Chen, H., Mao, Y., Chen, S., Dai, J., et al. (2020a). The relationship between media exposure and mental health problems during COVID-19 outbreak (in Chinese). Fudan Univ. J. Med. Sci. 47, 173-178. doi: 10.3969/j.issn.1672-8467.2020.02.005

Wang, Y., Wang, C., Liao, Z., Zhang, X., and Zhao, M. (2020b). A comparative analysis of anxiety and depression level among people and epidemic characteristics between COVID-19 and SARS (in Chinese). Life Sci. Res. 24, 180-186. doi: 10.16605/j.cnki.1007-7847.2020. 03.002

World Health Organization (2020). WHO Coronavirus Disease (COVID-19) Dashboard [Online]. Available online at: https://covid19.who.int/ (accessed July 1, 2020).

Wu, M., Han, H., Lin, T., Chen, M., Wu, J., Du, X., et al. (2020). Prevalence and risk factors of mental distress in China during the outbreak of COVID-19: a national cross-sectional survey. Brain Behav. 10:e01818. doi: 10.1002/brb3.1818

Wu, P., Fang, Y., Guan, Z., Fan, B., Kong, J., Yao, Z., et al. (2009). The psychological impact of the SARS epidemic on hospital employees in China: exposure, risk perception, and altruistic acceptance of risk. Can. J. Psychiatry 54, 302-311. doi: 10.1177/070674370905400504

Wu, T., Jia, X., Shi, H., Niu, J., Yin, X., Xie, J., et al. (2020). Prevalence of mental health problems during the COVID-19 pandemic: a systematic review and meta-analysis. J. Affect. Disord. 281, 91-98. doi: 10.1016/j.jad.2020.11.117

Xiao, J., Chen, Y., Fang, F., Liu, W., Zhong, Y., Tao, J., et al. (2020). Public anxiety and depression and its influencing factors under public health emergencies (in Chinese). Mod. Prev. Med. 47, 3557-3562.

Yáñez, J. A., Afshar Jahanshahi, A., Alvarez-Risco, A., Li, J., and Zhang, S. X. (2020). Anxiety, distress, and turnover intention of healthcare workers in peru by their distance to the epicenter during the COVID-19 crisis. Am. J. Trop. Med. Hyg. 103, 1614-1620. doi: 10.4269/ajtmh.20-0800

Yang, B., Yang, Y., Jia, Y., Li, Z., Qin, X., and Duan, J. (2020). Survey on the psychological state of the masses in the plain area of chengdu during the epidemic of COVID-19 (in Chinese). World Latest Med. Inf. 20, 251-253. doi: 10.3969/j.issn.1671-3141.2020.43.134

Yang, L., Zhang, Y., Xu, Y., Zheng, J., and Lin, Z. (2020). Investigation on psychological stress in fighting against corona virus disease 2019 among community residents (in Chinese). Chin. Nurs. Res. 34, 1140-1145. doi: 10.12102/j.issn.1009-6493.2020.07.009

Yang, S., Lin, H., Zhu, J., Chen, Y., Wang, N., Zhao, Q., et al. (2020). Depression and anxiety symptoms among returning workers during the COVID-19 period in East China. Soc. Psychiatry Psychiatr. Epidemiol. doi: 10.1007/s00127-020-01983-w. [Epub ahead of print].

Yang, T., Qu, X., and Wang, H. (2020). Mental health of community residents in Wuhan during the epidemic of COVID-19 and the influencing factors (in Chinese). J. Nurs. Sci. 35, 76-78. doi: 10.3870/j.issn.1001-4152.2020.13.076

Yang, X., Xiong, Z., Li, Z., Li, X., Xiang, W., Yuan, Y., et al. (2020). Perceived psychological stress and associated factors in the early stages of the coronavirus disease 2019 (COVID-19) epidemic: evidence from the general Chinese population. PLoS ONE 15:e0243605. doi: 10.1371/journal.pone. 0243605

Yang, Y., Liu, K., Li, S., and Shu, M. (2020). Social media activities, emotion regulation strategies, and their interactions on people's mental health in covid-19 pandemic. Int. J. Environ. Res. Public Health 17, 1-16. doi: $10.3390 /$ ijerph17238931

Yao, H., Chen, J.-H., and Xu, Y.-F. (2020). Patients with mental health disorders in the COVID-19 epidemic. Lancet Psychiatry 7:e21. doi: 10.1016/S2215-0366(20)30090-0

Yu, Y., Tan, D., Wan, Y., Wang, Y., and Jiang, X. (2020). Investigation and analysis of anxiety state of residents in enshi during the COVID-19 (in Chinese). World Latest Med. Inf. 20, 267-269. doi: 10.3969/j.issn.1671-3141.2020.78.117

Zhang, J., Li, P., and Li, Z. (2020). Analysis of influencing factors of community female residents' psychology and evaluation of intervention effect during the outbreak of novel coronavirus pneumonia (in Chinese). J. Changzhi Med. Coll. $34,81-86$.

Zhang, L., Ma, M., Li, D., and Xin, Z. (2020a). The psychological typhoon eye effect during the COVID-19 outbreak in China: the role of coping efficacy and perceived threat. Global. Health 16:105. doi: 10.1186/s12992-020-00626-8

Zhang, L., Zhang, B., and $\mathrm{Hu}$, L. (2020b). The relationship between perceived stress and sleep quality of Wuhan residents during COVID-19 outbreak: psychological resilience as a moderator (in Chinese). Chin. J. Dis. Control Prev. 24, 638-642. doi: 10.16462/j.cnki.zhjbkz.2020.06.004

Zhang, S. X., Huang, H., and Wei, F. (2020). Geographical distance to the epicenter of Covid-19 predicts the burnout of the working population: ripple effect or typhoon eye effect? Psychiatry Res. 288:112998. doi: 10.1016/j.psychres.2020.112998 
Zhang, Y., Cao, X., Wang, P., Wang, G., Lei, G., Shou, Z., et al. (2020). Emotional "inflection point" in public health emergencies with the 2019 new coronavirus pneumonia (NCP) in China. J. Affect. Disord. 276, 797-803. doi: 10.1016/j.jad.2020.07.097

Zhao, X., Lan, M., Li, H., and Yang, J. (2020). Perceived stress and sleep quality among the non-diseased general public in China during the 2019 coronavirus disease: a moderated mediation model. Sleep Med. 77, 339-345. doi: 10.1016/j.sleep.2020.05.021

Zhen, R., and Zhou, X. (2020). Predictive factors of public anxiety under the outbreak of COVID-19 (in Chinese). Chin. J. Appl. Psychol. 26, 99-107.

Zhong, X., Yuan, D., and Wang, B. (2020). Detection status and influencing factors of residents with symptoms of acute stress disorder during the COVID-19 (in Chinese). Sichuan Mental Health 33, 398-402. doi: 10.11886/scjsws20200419001

Zhou, Y., and Liu, Q. (2020). Analysis of the emotional response of residents under COVID-19 and its influencing factors (in Chinese). J. Front. Med. 10, 252-254.

Zhu, J., Su, L., Zhou, Y., Qiao, J., and Hu, W. (2020a). The effect of nationwide quarantine on anxiety levels during the COVID-19 outbreak in China. Brain Behav. 11:e01938. doi: 10.1002/brb3.1938

Zhu, J., Xu, N., Pan, Y., Ying, P., Ye, J., Liu, C., et al. (2020b). Investigation research on cognition, prevention and control behavior and psychosomatichealthy status of different types of adults during the epidemic period of corona virus disease-19 (in Chinese). China Med. 15, 816-820. doi: 10.3760/j.issn.1673-4777.2020.06.004

Zhu, X., Liu, D., Yan, F., Qu, W., Fan, H., Zhao, Y., et al. (2020). Psychological status of school students and employees during the COVID-19 epidemic (in Chinese). Chin. Mental Health J. 34, 549-554. doi: 10.3969/j.issn.1000-6729.2020.6.013

Zhu, Z., Liu, Q., Jiang, X., Manandhar, U., Luo, Z., Zheng, X., et al. (2020). The psychological status of people affected by the COVID-19 outbreak in China. J. Psychiatr. Res. 129, 1-7. doi: 10.1016/j.jpsychires.2020.05.026

Conflict of Interest: The authors declare that the research was conducted in the absence of any commercial or financial relationships that could be construed as a potential conflict of interest.

Copyright (c) 2021 Li, Zhang, Zhang, Luo, Wang, Wu, Zhu, Cui, Wang, Li, Zhu, Xu and Li. This is an open-access article distributed under the terms of the Creative Commons Attribution License (CC BY). The use, distribution or reproduction in other forums is permitted, provided the original author(s) and the copyright owner(s) are credited and that the original publication in this journal is cited, in accordance with accepted academic practice. No use, distribution or reproduction is permitted which does not comply with these terms. 